\author{
錯体重合法による $\mathrm{Bi}_{2.1} \mathrm{Sr}_{1.9-\mathrm{x}} \mathrm{La}_{\mathbf{x}} \mathrm{CuO}_{6+d}$ の合成とそのラマン散乱

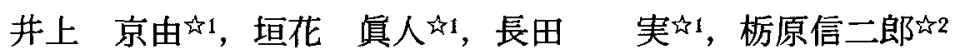 \\ 安岡宏放, 間崎 啓匡行, 八島 正知的1 \\ 的 東京工業大学応用七ラミックス研究所, 干226 横浜市粶区長律田町4259. \\ 社2 防衛大学校数学物理学教室, 干239 横須賀市走水1-10-20.
}

\title{
Polymerized Complex Synthesis and the Raman Scattering of $\mathrm{Bi}_{2.1} \mathrm{Sr}_{1.9-x} \mathrm{La}_{\mathbf{x}} \mathrm{CuO}_{6+d}$
}

\author{
Atsuyoshi Inoue ${ }^{\hbar 1}$, Masato Kakihara ${ }^{\natural 1}$, Minoru Osada ${ }^{\hbar 1}$, Shinjirou Tochihara ${ }^{\hbar 2}$ \\ Hiroshi Yasuoka ${ }^{\text {t2 }}$, Hiromasa Mazaki ${ }^{\text {th2 }}$ and Masatomo Yashima ${ }^{\text {th } 1}$ \\ 4i Materials and Structures Laboratory, Tokyo Institute of Technology, 4259 Nagatsuta Midori-ku, \\ Yokohama 226. 22 Department of Mathematics and Physics, The National Defense Academy, \\ 1-10-20 Hasirimizu, Yokosuka 239.
}

Received Ocrober 29, 1996

\section{SYNOPSIS}

High-purity polycrystalline samples of $\mathrm{Bi}_{21} \mathrm{Sr}_{1.9-x} \mathrm{La}_{x} \mathrm{CuO}_{6+d}$ with $\mathrm{x}=0-1$ have been prepared by the polymerized complex method. $\mathrm{X}$-ray powder ffffraction and complex magnetic susceptibility mesurements have shown that the samples are of a single-bulk $\mathrm{Bi} 2201$ phase without any impurity such as $\mathrm{Bi}_{17} \mathrm{Sr}_{16} \mathrm{Cu}_{7} \mathrm{O}_{y}, \mathrm{CuO}, \mathrm{Bi}_{2} \mathrm{Sr}_{3} \mathrm{Cu}_{2} \mathrm{O}_{y}$. The dependence of the superconducting transition temperature $T_{d}$ (onset) with increasing La content has a parabolic-like behavior with maximum $T_{\alpha}$ (onset) $=16.6 \mathrm{~K}$ at $x=0.3$. We heve investigated the effect of $\mathrm{La}$ substitution for $\mathrm{Sr}$ on Raman spectra of $\mathrm{Bi}_{2.1} \mathrm{Sr}_{1.9 . x} \mathrm{La}_{x} \mathrm{CuO}_{6+0}$. The apical-oxygen phonon at $\sim 630 \mathrm{~cm}^{-1}$ softens by $\sim 20 \mathrm{~cm}^{-2}$ with increasing La content, when $x$ goes from 0 to 1 . This change can be interpreted in terms of the charge redistribution induced by decreasing the $\mathrm{Cu}$ and $\mathrm{Bi}$ valences with $\mathrm{La}$ doping.

\section{KEY WORDS}

$\mathrm{Bi}_{2,1} \mathrm{Sr}_{1.9 .8} \mathrm{La}_{x} \mathrm{CuO}_{6+d}$ superconductor, Polymerized complex method, Complex magnetic susceptibility , Raman scattering

\section{1 粕言}

酸化物高温超伝導体の機棈を解釈する上で，ホー ル密度の変化に伴う諸物性の変化を調へることは 非常に重要である，p型超伝導体の原型である $\mathrm{La}_{2 \cdot \mathrm{x}} \mathrm{Sr}_{\mathrm{x}} \mathrm{CuO}_{4 \triangleleft}$ や $\mathrm{YBa}_{2} \mathrm{Cu}_{3} \mathrm{O}_{-\cdot d}$ では，ホール密度と超伝 導転移温度 $\left(T_{d}\right)$ に密接な相関関係があり、ホール 密度の変化に伴い $T_{\mathrm{c}}$ はベル型の相関関係を持つこと が広く知られている ${ }^{1,2)}$ ：この相関関係は，Bi系酸 化物超伝導体 $\mathrm{Bi}_{2} \mathrm{Sr}_{2} \mathrm{Ca}_{b-1} \mathrm{Cu}_{2} \mathrm{O}_{y}(n=1,2,3 ; \mathrm{Bi} 2201$, Bi2212，Bi2223)にも成立する，Bi2212においては, Caサイトに希土類（例えば，Y）を固換することに より，また，Bi2201においてもSrサイトによを置

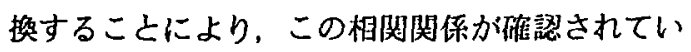

る3. このBi系酸化物超伝導体においてBi2201は, $\mathrm{n}=1$ であり，CuがOと八面体を檕成する(La, $\mathrm{M}_{2} \mathrm{CuO}$ 、 $(\mathrm{M}=\mathrm{Ca}, \mathrm{Sr})$ と同様の棈造を持っている.すなわち, $\mathrm{CuO}_{2}$ 面が一㕌のみであることから，ホール密度の 変化がTの変化に直接反映する重要な物質系である. しかしながら，（定比組成 $\mathrm{Bi}_{2.0} \mathrm{Sr}_{2.0} \mathrm{CuO}_{6+8}$ を持つ試 料の) $\mathrm{Sr}^{2+} \mathrm{La}^{3+}$ 置換量の增加に伴う $T_{\mathrm{c}}$ の変化では, 既往の矿究においてバラッキがみられる3-こ．この 一つの要因として，通常よく用いられている固相 法における烍成温度 $\left(800 \sim 900^{\circ} \mathrm{C}\right)$ か，斫究者に よって翼なっていることが背景として挙げられる。 この焜成温度の違いから，試料中の酸素量に違い が生じ，また，組成此にも定比組成 $\mathrm{Bi}_{20} \mathrm{Sr}_{2,0} \mathrm{CuO}_{8+0}$ 
からのずれが生してている考えられるＩdemotoら"9 は、Bi2201の相図を砄究し，大気中で $820 \sim 840^{\circ} \mathrm{C}$ の㮱成温度筑囲で，狭い組成の領域ではあるが， BiがSrサイトに少し固溶した組成を有する試料に おいて単相試料を得ることができたと報告してい る.

そこで，本研究では，同様のBi系超伝導体にお いて $\mathrm{Bi}_{2} \mathrm{Sr}_{2} \mathrm{Ca}_{1-x} \mathrm{Y}_{x} \mathrm{Cu}_{2} \mathrm{O}_{8+d}$ の良質な単相試料の合成に 成功し ${ }^{10)}$ ，また，酸化物高温超伝学体の均一合成に 有效であることが知られている鍇体重合法 ${ }^{11,12)}$ を用 い, $\mathrm{Bi}_{21} \mathrm{Sr}_{1.9-\mathrm{x}} \mathrm{La}_{\mathrm{x}} \mathrm{CuO}_{6+d}(\mathrm{x}=0-1)$ の組成を有する良質 な多結晶体試料を作製した，さらに， $\mathrm{Sr}^{2+} / \mathrm{La}^{3}$ 置換

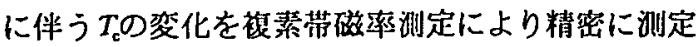
した. これに加え，ホール密度の変化に伴う電子 状態の変化を䂨筧するのに有效であるラマン散乱 湘定を実施した、これらの結果より，锥湘された ラマンスペクトルの変化をホール密度の変化に伴 う $T_{\mathrm{s}}$ 変化と関連づけて䛾諭する.

\section{2 試料作製及び実験方法}

\section{1 試料作製及び評洒}

$\mathrm{Bi}_{2,1} \mathrm{Sr}_{1.9 . x} \mathrm{La}_{x} \mathrm{CuO}_{6+0}(x=0.0,0.1,0.2,0.3,0.4,0.5$, $0.6,0.8,1.0)$ の試料は，クエン酸とエチレングリ コールを用いた錯体重合法により作製した．各金 属塩は，それぞれ $\mathrm{SrCO}_{3}, \mathrm{CuCO}_{3}$ の高純度炭酸塩

（セイミケミカル株式会社製， $\mathrm{CuCO}_{3}$ は純度99.99 \%以上， $\mathrm{SrCO}_{3}$ は純度 $99.9 \%$ 以上）およびBi( $\left(\mathrm{NO}_{3}\right)_{3}$ ・ $5 \mathrm{H}_{2} \mathrm{O}, \mathrm{La}\left(\mathrm{NO}_{3}\right)_{3} \cdot 6 \mathrm{H}_{2} \mathrm{O}$ の硝酸塩（関東化学株式会社 製， $\mathrm{Bi}\left(\mathrm{NO}_{3}\right)_{3} \cdot 5 \mathrm{H}_{2} \mathrm{O}$ は純度 $99.5 \%$ 以上， $\mathrm{La}\left(\mathrm{NO}_{3}\right)_{3} \cdot$ $\mathrm{H}_{2} \mathrm{O}$ は純度 $99.99 \%$ 以上）を用いた。 クエン酸の力 ルボキシル基と金属イオンが錯形成するとき $\mathrm{Bi}$, Sr, La，Cuおよびクエン酸の何数をそれぞれ+3洒， +2洒，+3侕，+2何,-3洒であると仮定し，金属イオン のモル比か $\mathrm{Bi}: \mathrm{Sr}: \mathrm{La}: \mathrm{Cu}=2.1: 1.9-\mathrm{x}: \mathrm{x}: 1(0 \leqq$

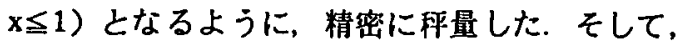
$\mathrm{Cu}, \mathrm{Sr}, \mathrm{La}$ 順にクエン酸とエチレングリコールの 透明な混合溶液に溶解させた。このとき，エチレ ングリコールは金属 $150 \mathrm{mmol}$ 当たり約 $200 \mathrm{ml}$ 用いた。 さらに別の容器でエチレングリコールに溶かした $\mathrm{Bi}\left(\mathrm{NO}_{3}\right)_{3} \cdot 5 \mathrm{H}_{2} \mathrm{O}$ を加えた後，完全に溶解させ，加熱 擋拌し，茶褐色のポリエステル樹脂を得た。これ を450 ㄷに設定したマントルヒーターで加熱分解さ せ，前取体粉末を得た。この前駆体粉末に対し， $800^{\circ} \mathrm{C}$ で6時間仮焟し，粉砕混合後， $830^{\circ} \mathrm{C}$ で12時間 烧成したささらに一軸加区でペレットに成型し， $850^{\circ} \mathrm{C}$ で24時間の焼成を行った：このとき，すべて 大気中で焼成した.

生成相の同定には，マックサイエンス社製 $\mathrm{MXP}^{3 \mathrm{~V} \wedge} \mathrm{X}$ 線粉林回折装置を用いた，格子定数の算 出には，Siを内部標準として加え，観测されたピー クを用い最小自乗法により求めた。

\section{2 複素帯磁率法 ${ }^{(3)}$}

超伝導転移温度 $(T)$ は，Hartshorn bridgeを用いた 複素芇磁率法 ${ }^{13}$ により测定した．この複素帯磁率 $\chi=\chi^{\prime}-\mathrm{i} \chi^{\prime \prime}$ の実数部 $\chi^{\prime}$ は試料の磁気遮敏効果 に対応し，虚数部の $\chi$ ”は試料中におけるエネル ギ一損失に対応している，試料内に温度勾配が生 じることを避け，測定結果の再現性を保証するた めに試料の温度は室温から $0.3 \mathrm{~K} / \mathrm{min}$ の割合でゅっ

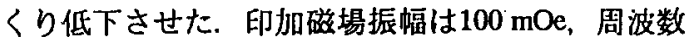
は132 Hzを用いた。

\section{3 ラマン散乱}

ラマンスペクトルの测定は，Jobin-Yvon/爱宕物 産社製T64000ラマンシステムにより行った．励起

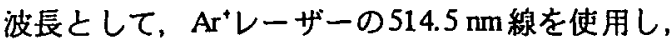
試料でのビーム径を $100 \mu \mathrm{m}$ 程度に集光し，散乱光 を後方散乱配置により测定した．試料の損傷を避 ける為，入射光のレーザー出力は試料上で 20 W/ $\mathrm{cm}^{2}$ 以下になるようにした，散乱光はJobin-Yvon/ 受宕物産社製T64000トリプルスペクトロメーター を用いて分光し，液体堂素で冷却した $\mathrm{CCD}$ (charge coupled deviœ)検出器を用いて検出した. 露光時間 は1200-1800秒，波数分解能は4 $\mathrm{cm}^{-1}$ 以下である。

\section{3 結果及び考察}

錯体重合法により作製した $\mathrm{Bi}_{2,1} \mathrm{Sr}_{1.9-\mathrm{x}} \mathrm{La}_{\mathbf{x}} \mathrm{CuO}_{6+0}$ $(\mathrm{x}=0.0,0.2,0.4,0.6,0.8,1.0) の$ 多結晶体に対 してX線粉末回折を行った．それぞれのX線粉末回 折図形を Fig.1に示す．X線粉末回折パターン上の 指数は，空間群 $4 / \mathrm{mmm}$ に属する正方晶の単位格子 を持つと仮定した場合に付けられるものである. 尚, 指数付けが行われていないピークは，変調棈 造の為に生じたものであり，観测されたピークの 同定には，Ikedaら "14)びIdemotoら”のX線粉末回折 図形を参照した，その結果，Bi2201の合成時にし ばしば混在が認められた不純物 $\left(\mathrm{Bi}_{17} \mathrm{Sr}_{16} \mathrm{Cu}_{7} \mathrm{O}_{y}\right.$, $\mathrm{CuO}, \mathrm{Bi}_{2} \mathrm{Sr}_{3} \mathrm{Cu}_{2} \mathrm{O}_{y}$ など）はいずれの組成でも検出さ れなかった，わずか 3 回の烧成により，単相であ る試料を合成することに成功した。 


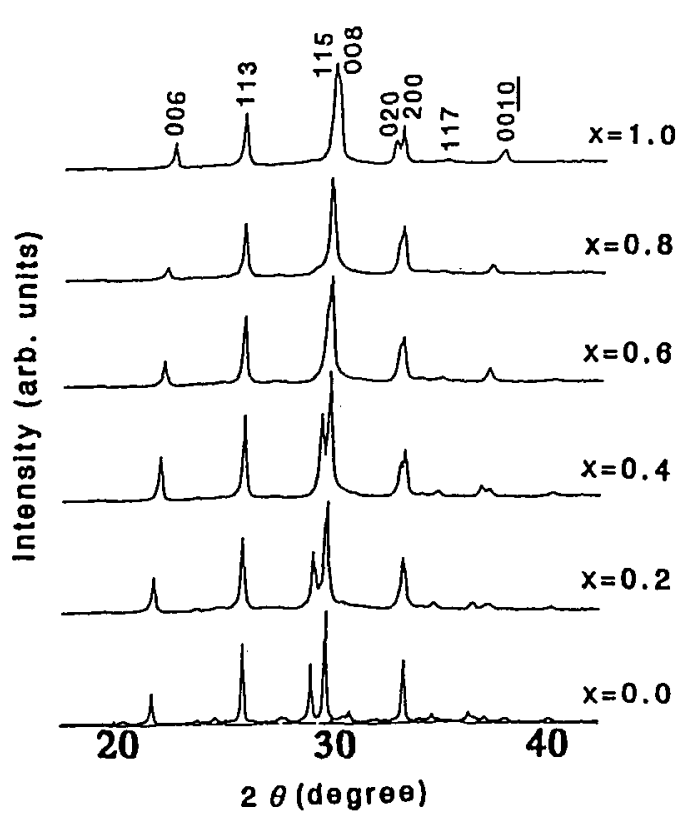

Fig. $1 \mathrm{X}$-ray pow der-diffraction patterns, using $\mathrm{Cu} \mathrm{K} \alpha$ radiation, $\mathrm{Bi}_{2.1} \mathrm{Sr}_{1.9-\mathrm{x}} \mathrm{La}_{\mathrm{x}} \mathrm{CuO}_{6+1}(\mathrm{x}=0.0,0.2,0.4,0.6$, $0.8,1.0)$ polycrystalline samples prepared by the polymerized complex method.

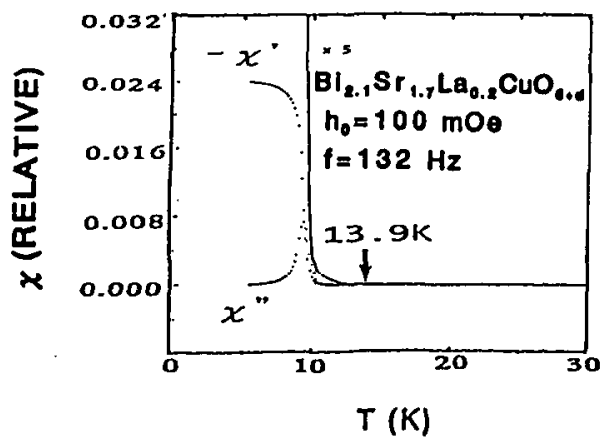

Fig.2 Real ( $\left.\chi^{\prime}\right)$ and imaginary ( $\left.\chi^{\prime \prime}\right)$ components of $\chi$ vs temperature for a polycrystalline sample of $\mathrm{Bi}_{2.1} \mathrm{Sr}_{1,7} \mathrm{La}_{0.2} \mathrm{CuO}_{6+\mathrm{d}}$. The amplitude of the applied field $\left(h_{0}\right)$ is $100 \mathrm{mOe}$ and the frequency $(f)$ is $132 \mathrm{~Hz}$.

Fig. $2 に \mathrm{Bi}_{2,1} \mathrm{Sr}_{1.2} \mathrm{La}_{0.2} \mathrm{CuO}_{6+\mathrm{d}}$ の複翡带磁率测定の結 果を示す. Tonset)は $\chi$ (oや゙ロ点からのずれより 精密に决定した．また， $\chi ”$ が転移幅に対応した 温度領域で単一ピークを形成していることから， 超伝導的な不純物を含まない単相であることがわ かった.

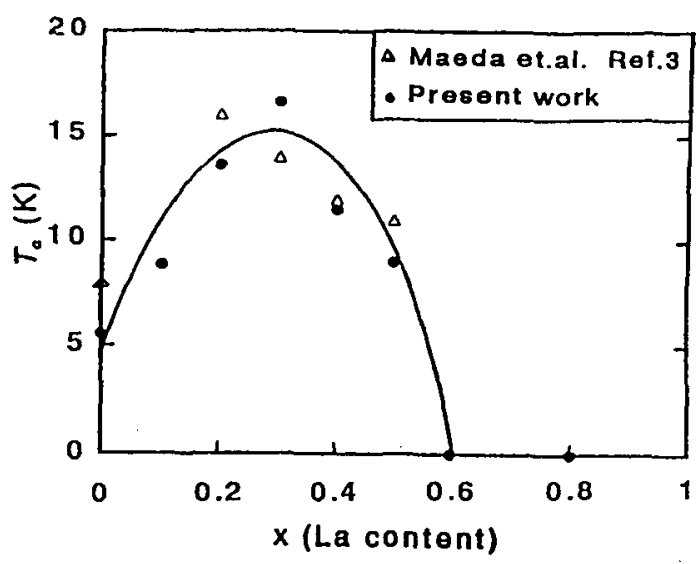

Fig. 3 Variation of the superconducting onset transition temperature ( $T_{e}$ onset) of $\mathrm{Bi}_{2,1} \mathrm{Sr}_{1.9 . x} \mathrm{La}_{x} \mathrm{CuO}_{6+\mathrm{d}}$ as a function of La content, $x$. For comparision, the reported data of ref. 3 are also plotted in the same figure.

次に，L置換量の増加に伴う $T_{\mathrm{c}}$ の裂化をFig.3に 示す. $\mathrm{Bi}_{2,1} \mathrm{Sr}_{1,9 . x} \mathrm{La}_{\mathrm{x}} \mathrm{CuO}_{6+0}(\mathrm{x}=0-1)$ のL置換量の增加に 伴うTの変化は，Maedaら゙によよる結果とほぼ一致し， La置換量の増加に伴いベル型の曲線を描くように 変化した. 本研究では， $x=0.3 の$ 組成のときに最も 高い $T_{c}=16.6 \mathrm{~K}$ 示した. また, $0.0<x<0.5$ の範囲 で超伝導転移が観測され，メ0.6の組成では液体へ リウム温度( $4.2 \mathrm{~K})$ 以上において超伝導を示さなかっ たこのT敨化は，最高の $T_{c}$ 示す時の最適なホー ル密度以上にある状態（オーバードープ状態）か ら、それ以下の状態 (アンダードープ状態)まて 変化するCuO 化である. そこで、ホール密度の変化に伴う $T_{\mathrm{c}}$ の変 化の関係について考察を深めるため，ホール密度 の変化に伴う電子状㿟悲の変化及び構造上の変化に 敏感であるラマン散乱測定を実施した。

$\mathrm{Bi}_{2,1} \mathrm{Sr}_{1.9 . x} \mathrm{La}_{\mathrm{x}} \mathrm{CuO}_{6+\mathrm{d}}(\mathrm{x}=0.0,0.2,0.4,0.6,0.8$, 1.0)のラマンスペクトルをFig.4に示す. ラマンモー

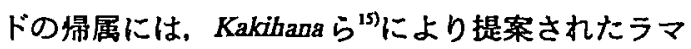
ンモードの慢属を用いた， $\mathrm{x}=0$ において $460 \mathrm{~cm}^{-1}$, $630 \mathrm{~cm}^{-1}$ 付近に観測されたモードは，それぞれBi-O 層の酸素に関するモ一ド $\left(\mathrm{O}_{\mathrm{B}}\right)$ ，頂点酸素に関するモー

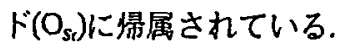

次に，La置換量の增加に伴うラマンスペクトル の変化について考察する．顕著な変化は， $630 \mathrm{~cm}^{-1}$ 近傍に現れる $\mathrm{O}_{\mathrm{s}}$ モードで観測され，La置換量の増 加に伴い単調に約 $20 \mathrm{~cm}^{-1}$ 低波数侧にシフトを示した. 


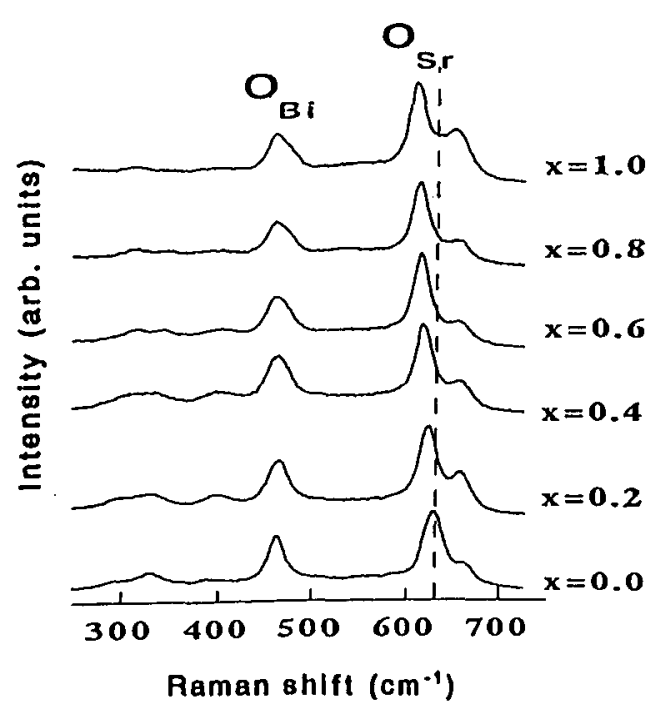

Fig.4 Raman spectra of $\mathrm{Bi}_{2.1} \mathrm{Sr}_{1.9-x} \mathrm{La}_{x} \mathrm{CuO}_{6+d}(\mathrm{x}=0.0,0.2$, $0.4,0.6,0.8,1.0$ ) polycrystalline samples using a conventional macro Raman configuration.
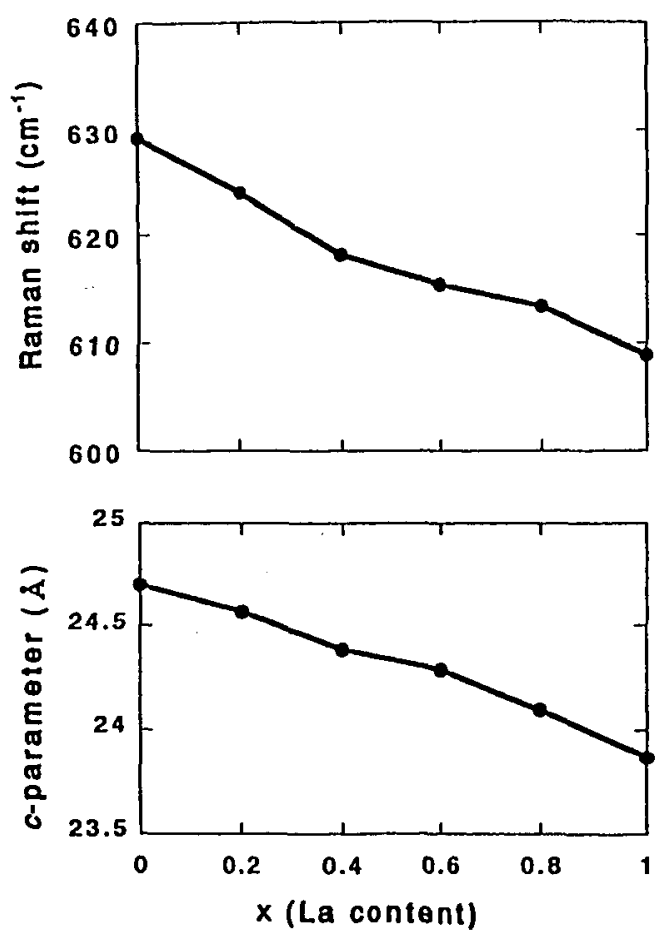

Fig.5 The frequency of the apex oxygen $\mathrm{O}_{\mathrm{S}_{\mathrm{I}}}$ Raman mode and the $c$ lattice parameter as a function of La content $x$ in $\mathrm{Bi}_{2,1} \mathrm{Sr}_{1.9-x} \mathrm{La}_{\mathbf{1}} \mathrm{CuO}_{6+\mathrm{d}}$.

ここで，格子の压縮や抬大により引き起こされる
フォノン周波数の変化を近似的に求めることので きるグリューナイぜン近似(Grüneisen approximation) を考える ${ }^{16,17}$.

$$
\gamma=-(1 / 3)[\mathrm{d}(\ln \nu) / \mathrm{d}(\ln c)]
$$

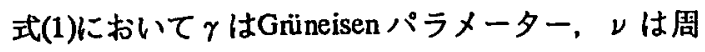
波数, $c$ は $c$ 柚長を示している. La置換量の增加 に伴う瞥造上の変化では, $\mathrm{Sr}^{2+}(1.26 \AA)$ と $\mathrm{La}^{3+}(1.16 \AA)$ のイオン半径の遠いから, 単調に $c$ 軸長が減少す ることを確認した(Fig.5). 式(1)によれば，La置換 量の增加に伴う $c$ 軸長の減少に起因した格子圧樎 の効果による $\mathrm{O}_{\mathrm{r}}$ モードの変化は，高波数侧にシフ トするはずである. しかし，観湘されたの、モード は低波数侧にシフトしており，全く逆の翂化をし ていることから，単純な格子王縮の效果から説朋 することはできない.

そこで，フォノン周波数が結合距離に反比例す $ろ^{(1)}$ ことに着目すると，既往の研究では，ヨードメ トリーによる娜定の結果 $\mathrm{Bi}, \mathrm{Cu}$ の価数が $\mathrm{x}=0.0$ の時 $\mathrm{Bi}^{+3.09} \mathrm{Cu}^{+206}$ から $\mathrm{x}=0.8$ の時 $\mathrm{Bi}^{43.06} \mathrm{Cu}^{+1.93}$ まで減少する こと9), 及びBi-O s $_{\text {r }}$-Cuの結合距焳が $\mathrm{x}=0.0$ の時 $4.55 \AA$ から $\mathrm{x}=0.30$ 時 $4.68 \AA$ まで拡大することが報告され ていることから ${ }^{8,19}$ ，次のように考えられる．すな わち，系全体の電気的中性条件を考虑すると， 2 佂のSrサイトに 3 価のLaが置換することにより， $\mathrm{Bi}, \mathrm{Cu}$ の洒数が減少し, $\mathrm{Bi}-\mathrm{O}_{\mathrm{s}}-\mathrm{Cu}$ の結合力が低下す る. そして, Bi-O に起因して，La置換量の增加に伴い頂点酸素 $\left(\mathrm{O}_{\mathrm{s}}\right)$ E一 ドが低波数側にシフトしたと解积することができ る. このことは, $\mathrm{Bi}_{2.1} \mathrm{Sr}_{1.9-x} \mathrm{La}_{x} \mathrm{CuO}_{6+d}$ のCuO $\mathrm{C}_{2}$ 面のホー 儿密度の減少に伴う超伝導転移温度 $(T)$ の变化の要 因の一つとして電荷移動効果が関与していること を示腹していると考えられる.

\section{4 まとめ}

錯体重合法を用いて $\mathrm{Bi}_{2,1} \mathrm{Sr}_{1.9-\mathrm{x}} \mathrm{La}_{\mathbf{x}} \mathrm{CuO}_{6+4}$ の前駆体を 合成し，従来の固相法に比へ短い焼成洔間で，ほ ぼ単相である試料を作製することに成功した。 ま た，復秦且磁率测定により精密に決定された Tronset)は， $\mathrm{Sr}^{2+} \mathrm{La}^{3+}$ 置換量の增加に伴い，ベル型の 曲線に沿って変化した，この時， $\mathrm{x}=0.3 て ゙ T_{\mathrm{cmax}}=$ $16.6 \mathrm{~K}$ を示した。 また， $0.0<x<0.50$ 範囲で超伝 導転移を示したが， $x>0.60$ 組成では超伝導を示さ 
なかった．さらに，ラマン散乱測定では， $630 \mathrm{~cm}^{\cdot 1}$ 近傍の $\mathrm{O}_{\mathrm{s}} モ$ ドにおいて, $\mathrm{Sr}^{2+} / \mathrm{La}^{3+}$ 置換量の増加に 伴い約 $20 \mathrm{~cm}^{-1}$ の低波数側へのシフトが観测された.

これらの変化は， $\mathrm{Sr}^{2+} / \mathrm{aa}^{3+}$ のイン半径の違いによ る単純な格子压縮の効果ては説明できず，Bi，Cuの 洒数が減少することに起因した変化であると解积 することができる，すなわち，観測されたラマン スペクトルの変化は， $\mathrm{CuO}_{2}$ 面のホール密度の減少 を反映しており，T航変化とも密接に関係している と考えられる。

\section{謝辞}

本研究は，文部省科学研究費補助金 (No.08455012及びNo.4482)の援助を受けて実施し たものである.

\section{女献}

1) See, e.g., M.S. Shafer, T.Penney and B.L. Olson: Phys. Rev., B36 (1987) 4047.

2) See, e.g., Y.Tokura, J.B. Torrance, T.C.Huang and A.I. Nazzal: Phys. Rev., B38 (1988) 7156.

3) A.Maeda, M Hase, I. Tukada, K.Noda, S.Takebayasi and K.Uchinokura: Phys. Rev., B41 (1990) 10.

4) Y.Idemoto, H.Tokunaga and K.Fueki: Physica., C231 (1994) 37.

5) C.V. Narashimha Rao, H.J. Trodahl and J.L. Tallon: Physica., C225 (1994) 45.

6) B.C. Sales and B.C. Chakoumakos: Phys. Rev., B43 (1991) 16.

7) A.J. Smits, W.J.Elion, J.M. van Ruitenbeek, L.J. de
Jongh and W.A. Groen: Physica, C199 (1992) 276.

8) N.R. Khasanova and E.V. Antipov: Physica., C246 (1995) 241.

9) Y. Idemoto, S. Kobayashi and K. Fueki: Physica., C229 (1994) 47.

10) 垣花道人，安彦媇哉，杉谷嘉則，長田実， 八島正知, 吉村荨弘, 間绮啓匡, 安岡宏: 粉体および粉末冶金, 42 (1995) 735 .

11）垣花真人，八島正知，吉村昌弘，間畸啓匡， 安岡宏: 粉体および粉末冶金, 40 (1993) 137.

12) M.Kakihana: J. Sol-Gel Sci. Tech., 6 (1996) 7.

13) T.Ishida and H.Mazaki: Phys. Rev., B20 (1979) 131.

14) Y.Ikeda, H.Ito, S.Shimomura, Y.Oue, K.Inaba, Z. Hiroi and M. Takano: Physica., C159 (1989) 93.

15) M.Kakihana, M.Osada, M.Käll, L.Börjesson, H. Mazaki, H. Yasuoka, M. Yashima and M. Yoshimura : Phys. Rev., B53 (1996) 11797.

16) C.Tomsen, R.Lin, M.Bauer, A.Wittlin, L. Genzel, M.Cardona, E.Schonherr, W.Bauhofer and W.König : Solid State Commun., 65 (1988) 55.

17) H.J. Trodahl, R.G. Buckley and C.K. Subramanian: Phys. Rev., B47 (1993) 47.

18) See, e.g., 藤森宏高, 垣花值人，八島正知, 間崎 啓匡, 安岡宏, 吉村昌弘: 粉体および粉末冶金, 42 (1995) 792.

19) C.C. Trardi, M.A. Subramanian, J.C. Calabrese, J. Gopalakrishnan, E.M. McCarrron, K.J. Morrissey, T.R. Askew, R.B. Flippen, U.Chowdhry and A.W. Sleight: Phys. Rev., B38 (1988) 225. 